\title{
Novel One-Pot Access to Diastereoisomeric Tertiary Phospholanes Oxides by Using Enantiomerically Pure Phospholane Oxides Under Catalyst-Free Conditions
}

\author{
Samia Guezane Lakoud, ${ }^{*[a]}$ Rim Aissa, ${ }^{[a]}$ Regis Guillot, ${ }^{[b]}$ Martial Toffano, ${ }^{[b]}$ and Louisa Aribi- \\ Zouioueche ${ }^{[a]}$
}

Dedicated to Professor Jean Claude FIAUD, pioneer in this research fields

\begin{abstract}
For the first time, enantiopure 1-r-oxo-2-c,5-t-diphenylphospholane was introduced as nucleophile in the multicomponent condensation reaction. Diastereoisomers of 2,5-diphenyl-1-oxo-1-[alkylphenyl-1-(phenylamino) methyl] phospholane derivatives were synthesized by one-pot process from aromatic aldehydes, anilines and enantiopure1-r-oxo-2-c,5$t$-diphenylphospholane under green and eco-compatible conditions. The reaction proceeds under catalyst-free conditions at room temperature within very short time (3 $\mathrm{min}$ ) in excellent yields (up to 95\%). An X-ray crystal structure has been obtained for 2,5diphenyl-1-oxo-1-[phenyl (phenylamino) methyl] phospholane.
\end{abstract}

\section{Introduction}

$P$-chiral organophosphorus compounds have been widely used in organometallic chemistry, homogeneous catalysis agrochemical and pharmaceutical industries. ${ }^{[1]}$ Phosphinylidene compounds are an important family of organophosphorus compounds, ${ }^{[2]}$ which includes phosphinates, $\mathrm{H}$-phosphonates, ${ }^{[3]} \mathrm{H}$-phosphinates and secondary or tertiary phosphine oxides. [4], [5] The $H$-phosphonate forms were widely used as direct precursor in Kabachnik-Fields reaction for $\alpha$ aminophosphonates, ${ }^{[6]}$ in Michaelis-Becker, Pudovic and Abramov reactions for amidophosphonates, phosphonic acids and hydroxyphosphonate derivatives in highly regio-, chemo- and stereoselective transformations. ${ }^{[7]} \mathrm{H}$-phosphine oxides prove valuable ligands in transition metal-catalyzed reactions ${ }^{\left[{ }^{[8]}\right.}$ Tertiary phosphine oxides are an important compounds class in organophosphorus chemistry showing a strong contribution in the field of organometallic asymmetric catalysis. ${ }^{[9]}$ Considerable attention is continuously devoted to non racemic tertiary phosphine oxides, since their reduction is one of the most useful methods for the preparation of optically active tertiary phosphines. ${ }^{[10]}$ Various approaches were also described to synthesize these precious targets: metal-free ${ }^{[11]}$ or transition metal-catalyzed cross-coupling reactions, ${ }^{[12]}$ Brønsted acid-catalyzed ${ }^{[13]}$ synthesis and Grignard reagents. ${ }^{[14]}$

Recently, secondary diphenylphosphine oxide was used in Kabachnik-Field reaction to form bis (phosphinoylmethyl) amine served as a precursor for an optically active bidentate $P$-ligand in the synthesis of a chiral platinum complex. ${ }^{[15]}$ Phospholane oxides and their derivatives have been subjected to hydrophosphinylation, ${ }^{[16]}$ and have emerged as effective pre-catalysts for an expanding new area of organocatalysts. ${ }^{[17]}$ Furthermore, in a pioneering work, Fiaud and Co-worker demonstrated the potential of 1-oxo-2c,5t-diphenylphospholane A, as an intermediate for the preparation of 1-r,2-c,5-ttriphenylphospholane ligand. ${ }^{[18]}$ Later this compound which presents a pseudo $C_{2}$ axis was used as a building block to develop P-aryl-2-c,5-t-diphenylphospholane ligands family, hydrophosphinylation ${ }^{[19]}$ or cross-coupling reaction. ${ }^{20]}$

Recently, Fiaud's acid or 1-oxo-1-hydroxy-2-c,5-t-diphenylphospholane, was introduced as an efficient chiral Brønsted acid catalyst for the synthesis of complex targets. ${ }^{[21]}$ Due to the electronic density at the phosphorus atom and the equilibrium form, the cyclic $1-H$-phosphine oxides are of exceptional interest as key intermediate to obtain original $P$ heterocyclic compounds. The monodentate phosphorus nature is likely to offer more efficient activity for metal or organocatalysis. ${ }^{[22]}$ For 2,5-disubstitued phospholane compounds, we supposed that the relative electronic richness of

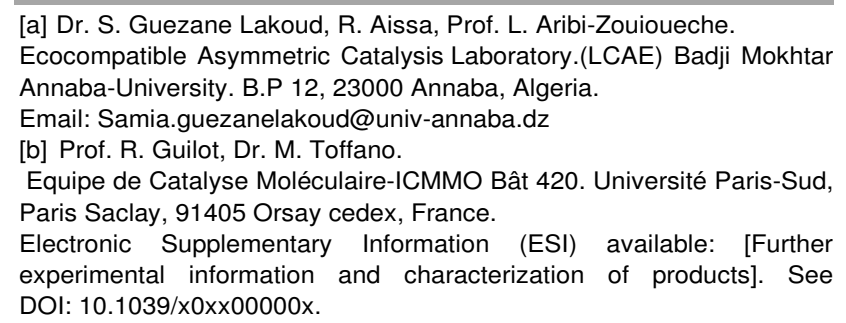

phosphorus atom is an opportunity to promote original reactivity to obtain interesting structures. Moreover, the non- 
stereogenic property of the phosphorus atom should avoid all problem of stereochemical integrity. The origin of chirality on the carbon frame as well as the five-membered cyclic chain would provide good asymmetric induction (Figure. 1).

With this in mind, by choosing a judicious reaction type, it is possible to access to new phosphorus compounds. Especially, the access to P-N compounds is particularly interesting for the development of new ligands or organocatalysts. ${ }^{\text {[23] }}$

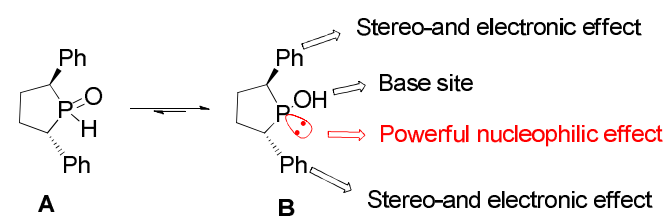

Figure. 1 Equilibrium form of enantiopure secondary phospholane oxide

Following our recent results concerning the enzyme-catalyzed synthesis of aminophosphonates and original bisaminophosphonates using free lipases and Candida antarctica $B$ lipase immobilized on acrylic resin $(C A L-B),{ }^{\left[{ }^{[6-b]},\right.}$, ${ }^{[24]}$ we propose herein to develop a multicomponent reaction for an access to an original chiral cyclic tertiary phosphine oxides via condensation reaction of aromatic aldehyde, aniline and cyclic enantiopure $H$-diphenyl phosphine oxide $\mathbf{A}$ as precursor. The reaction should proceed under free-catalysis, room temperature, short reaction times and environmentally benign reaction conditions. This study will be aimed at developing an efficient procedure for the preparation of the 2,5-diphenyl1-oxo-1-[alkyl phenyl-1-(phenylamino) methyl] phospholane $(\boldsymbol{R}, \boldsymbol{R}, \boldsymbol{R} / \boldsymbol{S})$-4a-j via modified Kabachnik-Fields reaction. These compounds would be obtained in two diastereomeric forms (Scheme 1).

\section{Litterature works}

Direct $\mathrm{C}-\mathrm{H}$ phosphonylation under transition-metal-free conditions. ${ }^{12 a}$

$$
\underbrace{>92 \%}_{\text {Yield }}
$$

Zr-catalyzed cycloalumination of alkenes in the one-pot synthesis of 3-R-1H-phospholane oxides. ${ }^{16 a}$

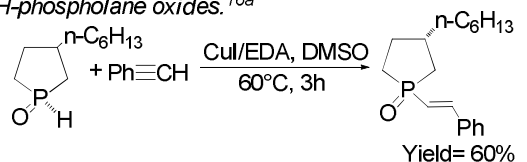

Metal-catalyzed hydrophosphinylation or coupling reactions of secondary 2,5diphenylphospholane oxide ${ }^{19 a}$
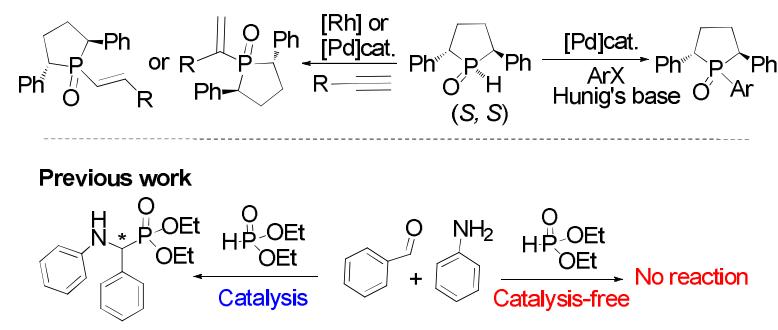

Yield : 96\%

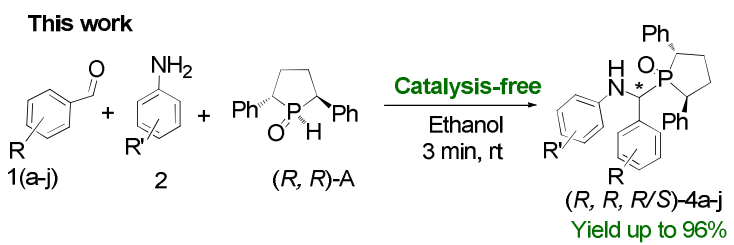

\section{Results and Discussion}


Initially, we used $\mathrm{H}$-diphenyl phosphine oxide $\left(\mathrm{Ph}_{2} \mathrm{POH}\right) \mathbf{C}$ in the Kabachnik-Fields condensation reaction without catalyst. The reaction proceeded through the condensation reaction of benzaldehyde (101 $\mathrm{mg}, 1 \mathrm{mmol})$, aniline (184 mg, $1 \mathrm{mmol})$ and $H$-diphenyl phosphine oxide $(256 \mathrm{mg}, 1 \mathrm{mmol}$ ) as model reaction, at room temperature in ethanol (1ml) (Table 1). The results show high reactivity of $H$-diphenyl phosphine oxide $\mathbf{C}$, giving the amino tertiary phosphine oxide $\mathbf{3 C}$ after 10 minutes with $45 \%$ yield (Table 1, entry 1 ). Increasing the reaction time to $30 \mathrm{~min}$ led to $\mathbf{3 C}$ compound in excellent isolated yield (Table 1, entry 2). It clearly appears that $H$-diphenyl phosphine oxide displayed better reactivity than $H$-diethylphosphite D which previously tested under catalyst-free conditions to give a-aminophosphonate 3D (Table 1, entry 3 vs 2).

Table. 1 Different phosphorus oxides tested as nucleophile in multicomponent Kabachnik-Fields reaction.

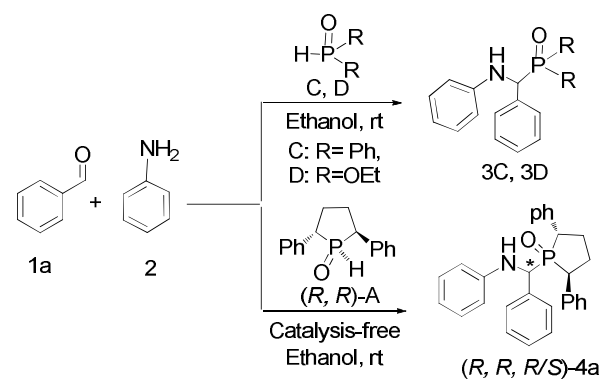

\begin{tabular}{|c|c|c|c|c|}
\hline Entry & Phosphorus oxide & Catalyst & Time/min & $\begin{array}{l}{\text { Yield }(\%)^{\mathrm{a}}}^{\text {/ Product }} \\
\text { / }\end{array}$ \\
\hline 1 & $\begin{array}{l}H \text {-diphenyl phosphine } \\
\text { oxide C }\end{array}$ & -- & 10 & $45 / 3 C$ \\
\hline 2 & $\begin{array}{l}\text { H-diphenyl phosphine } \\
\text { oxide C }\end{array}$ & -- & 30 & $80 / 3 \mathrm{C}$ \\
\hline 3 & H-diethyl phosphite $\mathbf{D}$ & -- & 60 & $---/ 3 D$ \\
\hline 4 & $\begin{array}{l}\text { Cycle } H \text {-phospholane } \\
\text { oxide }(\mathbf{R}, \mathbf{R})-\mathrm{A}\end{array}$ & -- & 3 & $96 / 4 a$ \\
\hline 5 & $\begin{array}{l}\text { Cycle } H \text {-phospholane } \\
\text { oxide }(\mathbf{R}, \mathbf{R})-\mathbf{A}\end{array}$ & $C A L-B$ & 3 & $96 / 4 a$ \\
\hline
\end{tabular}

${ }^{a}$ Isolated yield after crystallization in hexane.

Thereafter, and considering the reactivity of $H$-phosphine oxide $\mathbf{C}$, we have investigated for the first time the use of enantiopure 1-r-oxo-2-c,5-t-diphenylphospholane $\mathbf{A}$ as a nucleophile in Kabachnik-Fields multicomponent reaction. The general procedure involved the condensation of aromatic aldehyde, aniline and enantiopure secondary phospholane oxide A at room temperature in the presence of ethanol in two cases; without catalyst or with the use of the free lipases and Candida antarctica $B$ lipase immobilized on acrylicresin (CAL-B) (Table 1, entries 4 and 5) respectively.

2,5-diphenyl-1-oxo-1-[alkyl phenyl (phenylamino) methyl] phospholane 4a-j were obtained with high isolated yields in two diastereoisomers forms in a very short reaction time (3 $\mathrm{min}$ ) (Table 2). Indeed, the diastereomeric ratio (d.r.) is obtained from $73 / 27$ to $86 / 14$ depending the nature of the substrates and the electronic effects. The observed diastereoselectivities suggest a partial control by the chiral secondary phospholane oxide during the nucleophilic addition step. We also observed a drop of diastereoselectivity in the case of substrate $\mathbf{1 d}$ and $\mathbf{1 e}$. These results are probably due to the very high reactivity of the corresponding imine which reduces the enantioface recognition. All these compounds are novel in organophosphorus chemistry and the reactions were carried out through a very fast, atom economical and environmentally benign procedure.

${ }^{31} \mathrm{P}$ and ${ }^{1} \mathrm{H}$ NMR experiments were used for diastereomer quantification. The ${ }^{31} \mathrm{P}$ NMR spectra exhibited two peaks for the two diastereoisomers at around 62 and $61 \mathrm{ppm}$. From the ${ }^{1} \mathrm{H}$ NMR spectra, the proton of the three stereogenic carbons ${ }^{*} \mathrm{CHP}$ of two diastereoisomers appears clearly as a multiplet towards $4 \mathrm{ppm}$ due to the coupling with $\mathrm{P}$ atoms, and nitrogen protons $\mathrm{NH}$ of two diastereoisomers are very clearly exhibited as doublets around $5 \mathrm{ppm}$. The two diastereoisomeric 
compounds 4a were separated by crystallization in ethanol, single crystal X-ray diffraction analysis of the major diastereoisomer compound releaved the configuration $(2 R, 5 R, 1 R)$ (CCDC 1922735; contain(s) the supplementary crystallographic data for this paper. These data can be obtained free of charge from The Cambridge Crystallographic Data Centre via www.ccdc.cam.ac.uk/data request/cif (Figure. 2).

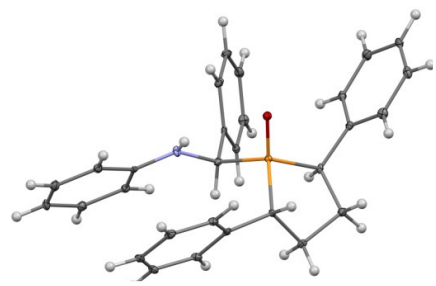

Figure. 2 X-ray crystal structure of $\mathbf{4 a}$

A possible mechanism for the formation of 2,5-diphenyl-1-oxo-1-[alkyl phenyl (phenylamino) methyl] phospholane 4 via Kabachnik-Fields condensation reaction with an equimolar quantity of starting materials (1/1/1 ratio) of aromatic aldehydes $\mathbf{1}$, anilines 2 and enantiopure secondary phospholane oxide $\mathbf{A}$ is shown in Scheme 2. Combining the view points developed by J. Zhang et al ${ }^{[25]}$ for the synthesis of $N$-phosphoramino $\alpha$-amino-alkyl phosphonates via diethyl phosphoramidate, ketones or aldehydes and 2-chloro-5,5-dimethyl-1,3,2-dioxaphosphane through Mannich type reactions, and on the basis of our observations as described above, we proposed that the imine was formed at the first time between an aldehyde and aniline, following by the nucleophilic attack of the tautomerized trivalent form of the enantiopure secondary phospholane oxide to re-face and si-face of the imine giving the two diastereoisomers of $\mathbf{4}$.

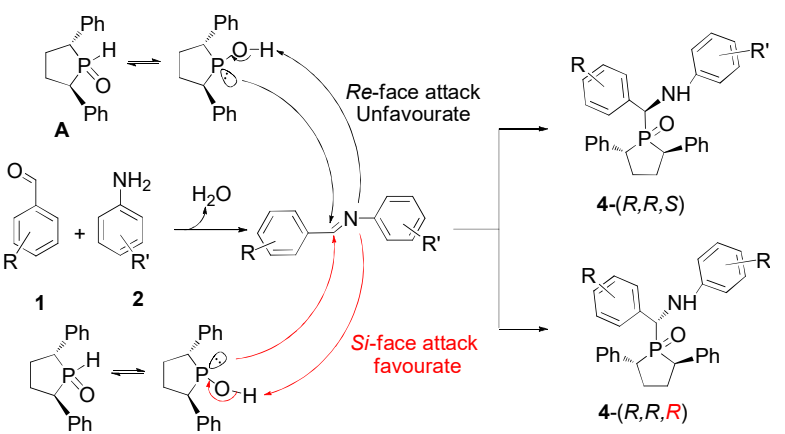

A

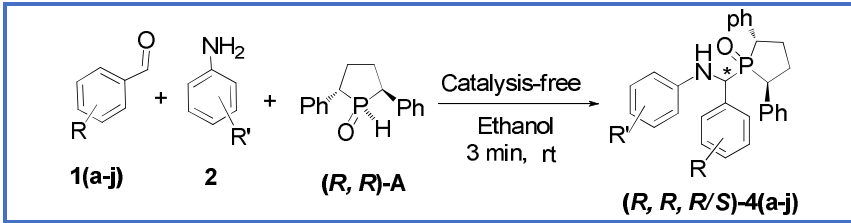


Table. 2 Synthesis of 2,5-diphenyl-1-oxo-1-[alkyl phenyl (phenylamino) methyl] phospholane 4a-j under catalyst freeconditions.

\section{Conclusions}

As a conclusion, we report an original one-pot synthesis of chiral 2,5-diphenyl-1-oxo-1-[alkyl phenyl (phenylamino) methyl] phospholane using enantiopure 1-r-oxo-2-c,5-t-diphenylphospholane A in multicomponent coupling reaction with aromatic aldehydes and anilines. An X-ray crystal structure has been obtained for a diastereoisomer of 2,5diphenyl-1-oxo-1-[phenyl (phenylamino) methyl] phospholane $4 \mathbf{a}$ and the configuration assigned as $(R, R, R)$. All compounds were obtained in high isolated yield (up > 95\%) under greener more efficient novel approach: atom-economic process, catalystfree, very short reaction time in green solvent, at room temperature and with purification by simple crystallization.

This is the first protocol of the use of enantiopure secondary phospholane oxide as the nucleophile in multicomponent reaction, providing anew access to valuable targets of the family of organophosphorus compounds.

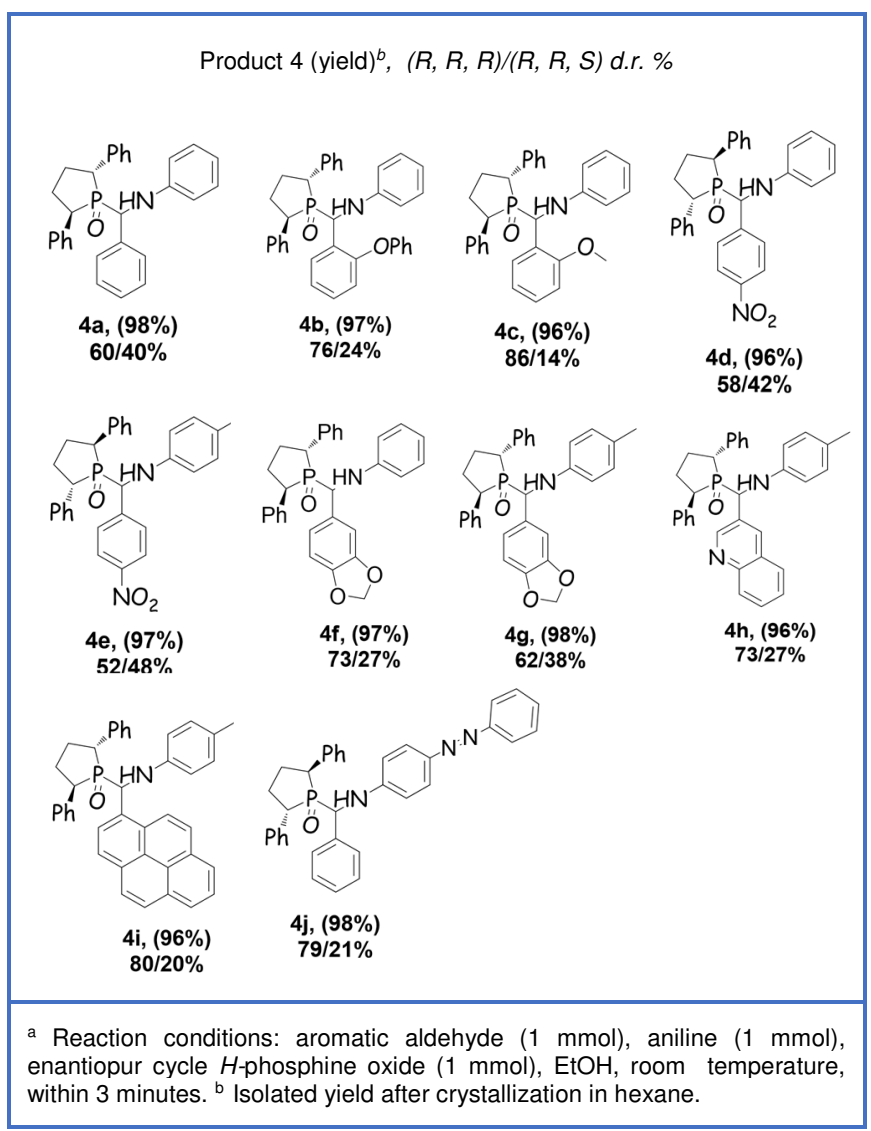

\section{Supporting Information Summary}

Supporting information file includes the general experimental procedure, compound characterization data and the ${ }^{1} \mathrm{H},{ }^{13} \mathrm{C}$ and ${ }^{31} \mathrm{P}$ NMR spectra and HRMS of all the compounds.

\section{Acknowledgements}

The Algerian Ministry of Higher Education and Scientific Research (MESRS, FNR 2000) is gratefully acknowledged for financial support of this work.

Keywords: Cyclic enantiopure, H-diphenyl phosphine oxide, Kabachnik-Fields reaction, Multicomponent reactions, Secondary phosphine oxides, Tertiary phosphine oxides.

[1] a) T. Baumgartner, R. Reau, Chem. Rev. 2006, 106, 4681-4727 b) S. U. Deshmukh, K. R. Kharat, A. R. Yadav, S. U. Shisodia, M. G. Damale, J. N. Sangshetti, R. P. Pawar, ChemistrySelect. 2018, 3, 5552 - 5558.

[2] a) T. Leon, M. Parera, A. Roglans, A. Riera, X. Verdaguer. Chem. Int. Ed. 2012, 51, 1-6. b) K. D. Troev, Reactivity of P-H Group of Phosphorus Base Compounds, Academic Press, Elsevier. 2018. c) L. Coudray, J. L. Montchamp, Eur. J. Org. Chem. 2008, 21, 3601-3613.

[3] N. Powles, J. Atherton M. I. Page, Org. Biomol. Chem, 2012, 10, 5940.

[4] a) H. Zhiming W. X. Li, Q. Yu, Z. Wang, Tetrahedron. 2016, 72, 7594e7598; b) G. Hu, W. Chen, T. Fu, Z. Peng, H. Qiao, Y. Gao, Y Zhao. Org Lett. 2013, 15, 5362-5365.

[5] T. M. Shaikh, C-M. Weng, F-E. Hong, Coord. Chem. Rev. 2012, 256, 771-803.

[6] a) S. Guezane-Lakoud, M. Merabet-Khelassi, L. Aribi-Zouioueche, Res. Chem. Intermed. 2016, 42, 4403-4415; b) S. Guezane-Lakoud, M. Toffano, L. Aribi-Zouioueche, Heteroatom Chem. 2017, 28, e21408; c) K. V. Turcheniuk, V. P. Kukhar, G-V. Roschenthaler, J. L. Acena, V. A. Soloshonokcd, A. E. Sorochinsky, RSC Adv. 2013, 3, 6693-6716.

[7] a) J. Lewkowski, R. Karpowicz, M. Morawska, P. Rychter, D. Rogacz, K. Lewicka, P. Dobrzynski, RSC Adv. 2017, 7, 38399; b) D. Zhao and R. Wang, Chem. Soc. Rev. 2012, 41, 2095-2108, c) A. R. Choudhury, S. Mukherjee, Chem. Sci. 2016, 7, 6940-6945.

[8] a) X-b. Jiang, A. J. Minnaard, B. Hessen, B. L. Feringa, A. L. L. Duchateau, J. G. O. Andrien, J. A. F. Boogers, J. G. de Vries, Org. Lett. 2003, 5, 1503-1506; b) N. V. Dubrovina, A. Börner, Angew. Chem. 2004, 116, 6007-6010; Angew. Chem. Int. Ed. 2004, 43, 5883-5886; c) A, Galland, C. Dobrota, M. Toffano, J-C. Fiaud, Tetrahedron: Asymmetry. 2006, 17, 2354-2357.

[9] a) Phosphorus Ligands in Asymmetric Catalysis, Vol. 1, 2 and 3 (Ed: A. Börner), Wiley-VCH, Weinheim. 2008; b) L. Kollár, G. Keglevich, Chem. Rev. 2010, 110, 4257-4302.

[10] a) G. Zon and K. Mislow, The Chemistry of Organophosphorus Compounds I, Springer. 1971, pp. 61-94; b) K. Naumann, G. Zon, K. Mislow, J. Am. Chem. Soc. 1969, 91, 2788-2789; c) K. E. DeBruin, G. Zon, K. Naumann, K. Mislow, J. Am. Chem. Soc. 1969, 91, 7027-7030; d) D. 
Herault, D. H. Nguyen, D. Nuel, G. Buono, Chem. Soc. Rev. 2015, 44, 2508-2528; e) S. Sowa, M. Stankevič, A. Szmigielska, H. Małuszyńska, A. E. Kozioł, K. M. Pietrusiewicz. J. Org. Chem. 2015, 80, 1672-1688; f) E. Podyacheva, E .Kuchuk, D. Chusov, Tetrahedron Lett. 2019, 60, 575-582.

[11] a) M. Gao, Y. Li, L. Xie, R. Chauvin, X. Cui. Chem. Commun. 2016, 52, 2846-2849; b) Ji-Y. Du, Y-H. Ma, R-Q. Yuan, N. Xin, S-Z Nie, C-L. Ma, C-Z Li, C-Q Zhao, Org. Lett. 2018, 2, 477-480.

[12] a) J. Chrzanowski, D. Krasowska, M. Urbaniak, L. Sieroń, P. Pokora-Sobczak, O. M. Demchuk, J. Drabowicz, Eur. J. Org. Chem. 2018, 33, 4614-4627; b) S. M. Rummelt, M. Ranocchiari, J. A. van Bokhoven, Org. Lett. 2012, 14, 2188-2190; c) J-Q. Zhang, T. Chen, J-S. Zhang, L-Bi. Han, Org. Lett. 2017, 19, 4692-4695; d) M. Toffano, C. Dobrota, J-C. Fiaud, Eur. J. Org. Chem. 2006, 650-656.

[13] L. Chen, Y-X. Zou, X-Y. Fang, J. Wu, and X-H. Sun, Org. Biomol. Chem. 2018, 16, 7417.

[14] Y. Nishiyama, Y. Hazama, S. Yoshida, T. Hosoya, Org. Lett. 2017, 19, 3899-3902.

[15] E. Bálint, Á. Tajti, D. Kalocsai, B. Mátravölgyi, K. Karaghiosoff, M. Czugler, G. Keglevich, Tetrahedron. 2017, 73, 5659-5667.

[16] a) L. K. Dil'mukhametova, T. V. Tyumkina, V. A. Dyakonov, U. M. Dzhemilev, Mendeleev Commun. 2017, 27, 23-25; b) G. Keglevich, N. Z. Kiss, A. Grün, E. Bálint, Synthesis. 2017, 49, 3069-3083; c) A. V. Shamsieva, E. I. Musina, K. R. Trigulova, A. A. Karasik, O. G. Sinyashin, Phosphorus, Sulfur, and Silicon. 2016, 191, 1630-1631.

[17] H. A. van Kalkeren, F. L. van Delft, F. P. J. T. Rutjes. ChemSusChem. 2013, 6, 1615-1624.

[18] F. Guillen, J.-C. Fiaud, Tetrahedron Lett. 1999, 40, 2939.

[19] 13 d); a) F. Guillen, M. Rivard, M. Toffano, J-Y Legros, J-C. Daran, J-C Fiaud, Tetrahedron. 2002, 58, 5895-5904; b) A. Duraud, M. Toffano, J.-C. Fiaud, Eur. J. Org. Chem. 2009, 26, 4400-4403.

[20] M. Cieslikiewicz, A. Bouet, S. Jugé, M. Toffano, J. Bayardon, C. West, K. Lewinski, I. Gillaizeau, Eur. J. Org. Chem. 2012, 6, 1101-1106.

[21] S. Chatterjee, L. Hintermann, M. Mandal, A. Achari, S. Gupta, P. Jaisankar, Org Lett. 2017, 19, 3426-3429.

[22] a) F. Lagasse, H. B. Kagan, Chem. Pharm. Bull. 2000, 48, 315-324; b) V. Komarov, A. Börner, Angew. Chem. Int. Ed. 2001, 40, 1197-1200;

H. Guo, Y. C. Fan, Z.Sun, Y. Wu, O. Kwon, Chem. Rev. 2018, 118, 10049-10293.

[23] a) M. P. Carroll, P. J. Guiry, Chem. Soc. Rev. 2014, 43, 819-833; b) W. Lia, J. Zhang. Chem. Soc. Rev. 2016, 45, 1657-1677; c) H. Ni, WL. Chan, Y. Lu, Chem. Rev. 2018, 118, 9344-9411.

[24] R. Aissa, S. Guezane-Lakoud, E. Kolodziej, M. Toffano, L. Aribi-Zouioueche, New. J. Chem. 2019, 43, 8153-8159.

[25] J. Zhang, Z. Cui, F. Wang, Y. Wang, Z. Miao, R. Chen, Green Chem. 2007, 9, 1341-1345. 